\title{
MEMÓRIA DE EVENTOS ENOS NA PRECIPITAÇÃO DA AMÉRICA DO SUL
}

\author{
Elaine Rosângela Leutwiler Di Giacomo Silva ${ }^{1}$ \\ Maria Elisa Siqueira Silva ${ }^{2}$
}

RESUMO: Neste estudo, buscou-se identificar as áreas de precipitação na América do Sul (AS) mais bem correlacionadas linearmente com a temperatura de superfície do oceano (TSM), nas regiões de Niño 1+2, 3, 3.4 e 4 do Pacífico Equatorial, na escala mensal. Os cálculos foram realizados para dados com e sem defasagem temporal, para o período de 1978 a 2005. Além da TSM, foram considerados o Índice de Oscilação Sul e o Multivariate ENSO Index. Áreas com maiores valores de correlação positiva e negativa foram encontradas, respectivamente, ao sul do Brasil, nordeste da Argentina e Paraguai e, ao norte da AS. A precipitação da região norte da AS apresenta altos valores de correlação com os índices climáticos oceânicos para defasagens maiores que a precipitação da região sudeste. Para defasagens temporais maiores que seis meses, os valores de correlação não são estatisticamente significativos. Assim, sugere-se que o sinal do Pacífico seja mais persistente na precipitação do norte da AS em comparação à precipitação da região sudeste. Em valores absolutos, o El Niño-Oscilação Sul está mais relacionado à precipitação da região Norte do Brasil enquanto que em valores relativos à precipitação da região Nordeste do Brasil apresenta maior decréscimo para casos de El Niño.

Palavras-chave: temperatura da superfície do mar; regiões de Niño; defasagem temporal; precipitação mensal; América do Sul.

\section{ENSO MEMORY IN SOUTH AMERICA PRECIPITATION}

ABSTRACT: We sought to identify in this study the linear correlation between sea surface temperature (SST) in the equatorial Pacific areas of Niño 1+2, 3, 3.4 and 4 and the monthly precipitation over South America (SA) with and without temporal lag, during the period 1978-2005. In addition to the SST, we considered the Southern Oscillation and the Multivariate ENSO Indices on correlation computation. Areas with higher positive and negative correlation values were found, respectively, to the south of Brazil, northeast Argentina and Paraguay, and, to the north of South America. The precipitation observed in the northern region presents correlation values for larger temporal lags than the one observed in southeastern South America. Lagged correlation for more than six month are not statistically significant both for north and southeast regions. The analysis suggests that the equatorial Pacific provides more direct influence in precipitation over the north South America than over southeastern areas. In absolute values, the El Niño-Southern Oscillation events are more related to precipitation over northern Brazil, on the other hand, for relative values, the Northeast region shows the highest decreasing in precipitation.

Keywords: sea surface temperature; Niño regions; time lag; monthly precipitation; South America

1. Universidade de São Paulo (laine.usp@gmail.com).

2. Universidade de São Paulo (mariaelisa.siqueirasilva@gmail.com). 


\section{INTRODUÇÃO}

A precipitação anual na América do Sul (AS) é caracterizada por altos índices na região norte, com valores superiores a 3000 mm no litoral do Amapá (MARENGO e NOBRE, 2009; NIMER, 1979), e é modulada pelo deslocamento meridional da Zona de Convergência Intertropical (ZCIT) no decorrer do ano. Durante o verão do hemisfério sul, a formação e a intensificação da Zona de Convergência do Atlântico Sul (ZCAS), associada à intensificação da convecção local sobre o centro-norte da AS, contribuem para elevados índices de precipitação, tanto na região sudeste quanto nas regiões centro-oeste e norte.

Devido à grande extensão do território sulamericano, vários são os padrões climáticos sazonais encontrados em suas diversas regiões, formados pela atuação de distintos sistemas atmosféricos. No norte da AS, particularmente na região Amazônica brasileira, Marengo e Nobre (2009) indicam a existência de três núcleos distintos de precipitação intensa: no extremo noroeste da Amazônia, onde os máximos de chuva predominam de junho a agosto; na região central amazônica, com máximos de precipitação que ocorrem de março a maio e, no sul da região, com máximos de chuva concentrados de janeiro a março, coincidindo com a época chuvosa do sudeste do Brasil.

De maneira geral, os maiores volumes de precipitação no centro norte da AS ocorrem durante o verão e estão associados à formação da Baixa do Chaco (GAN et al., 2004) em níveis baixos, devido ao maior aquecimento da superfície e das camadas atmosféricas adjacentes. Em altos níveis atmosféricos, e associada à da Baixa do Chaco, aparece, durante o verão, a Alta da Bolívia, sistema de alta pressão (LENTERS e COOK, 1997; MOLION, 1987).

De novembro a janeiro, durante o verão, é observado o desenvolvimento do Vórtice Ciclônico de Altos Níveis (VCAN), a leste da Alta da Bolívia (FERREIRA et al., 2009), contribuindo para definir as condições de tempo sobre a região nordeste do Brasil. No centro do VCAN desenvolve-se movimento vertical descendente, enquanto que nas bordas, há movimento ascendente do ar, contribuindo para a formação de nebulosidade e chuva nestas áreas.

Na faixa norte do nordeste do Brasil, por influência do deslocamento da ZCIT para o sul, os máximos de precipitação ocorrem entre março e abril. Na faixa leste, os máximos da precipitação ocorrem entre maio e julho devido à intensificação dos ventos de leste associados à alta subtropical do Atlântico Sul (KOUSKY, 1979).

Assim, a região central do nordeste do Brasil (sertão) sofre a influência de sistemas atmosféricos que não contribuem significativamente para a formação de nebulosidade e chuva. Localizando-se na mesma faixa latitudinal, a região central do nordeste do Brasil apresenta totais anuais de precipitação bem inferiores aos observados na região Amazônica, em média, da ordem de $20 \%$ do observado na Amazônia (KOUSKY; CHU, 1978).

A região sudeste do Brasil apresenta os maiores volumes de precipitação durante o verão devido à atuação da convecção por aquecimento local e da influência da ZCAS. O estudo da variabilidade interanual sobre o início da estação chuvosa do sudeste do Brasil indica que a estação tende a iniciar mais cedo em anos caracterizados por anomalias positivas da temperatura da superfície do mar (TSM) no oceano Pacífico Equatorial e, mais tarde, em anos quando estas anomalias de TSM são negativas (ALVES et al. 2005). Na região central do 
Brasil, o acumulado máximo de chuva ocorre no trimestre de dezembro a fevereiro (ALVES, 2009), também caracterizado por condições climáticas tropicais.

A região sul do Brasil, localizada em áreas subtropicais e de latitudes médias, apresenta chuvas mais bem distribuídas ao longo de todo o ano, tanto devido à atuação da convecção local, durante o verão, como pela atuação de frentes frias que passam pela região. $O$ norte da região sul do Brasil apresenta regime de chuva com valores máximos durante o verão do hemisfério sul (dez-mar), e o sul da região sul apresenta máximos de precipitação durante o inverno, devido à passagem mais frequente de frentes frias (GRIMM et al. 1998; GRIMM, 2009).

Apesar da sazonalidade da precipitação nas diversas áreas da AS ser relativamente bem conhecida, com a identificação espacial e temporal dos principais sistemas atmosféricos atuantes, sua variabilidade climática interanual necessita ser mais bem compreendida. Eventos El Niño-Oscilação Sul (ENOS), são frequentemente associados a anomalias de precipitação e temperatura do ar em todo o globo, tal como descrito por Horel e Wallace (1981), Rasmunsson e Carpenter (1983), Ropelewski e Ralpert (1987), Kane (1997), Grimm et al. (1998; 2003), Ambrizzi et al. (2002) e Ambrizzi (2003).

No início do século XX, cientistas observaram que oscilações atmosféricas e oceânicas poderiam estar associadas ao comportamento climático de áreas remotas tal como apontado nos estudos de Walker (1924); Walker e Bliss (1932); Bjerkness (1969). Especificamente em relação aos oceanos, Wallace e Gutzler (1981), Van Loon e Rogers (1978 e 1979) indicaram sua associação com a variabilidade climática em regiões remotas.

Em diversas localidades do globo, as anomalias extremas de precipitação e temperatura do ar são muitas vezes associadas a eventos anômalos de aquecimento e resfriamento dos oceanos, como ocorre com o evento ENOS, fenômeno climático associado a padrões espaciais de anomalias de TSM no oceano Pacífico, e às teleconexões atmosféricas. À associação das condições climáticas de distintas regiões dá-se o nome de teleconexão (AMBRIZZI, 2003).

Através do estudo de correlação linear entre dados de pressão atmosférica, temperatura do ar e precipitação, Walker (1924) identificou três padrões de teleconexões, dois no hemisfério norte, a Oscilação do Atlântico Norte (OAN), e a Oscilação do Pacífico Norte (OPN), e um no hemisfério sul, a Oscilação Sul (OS).

Com base no conjunto de dados da OS, Walker e Bliss (1932, p. 60) propuseram um complicado conjunto de equações na tentativa de explicar a variância dos padrões de pressão atmosférica, temperatura e precipitação em várias localidades do globo, dando origem mais tarde, ao que ficou conhecido como Índice de Oscilação Sul (IOS)3. Atualmente - IOS é estimado a partir das flutuações dos valores de pressão em superfície em duas regiões do Pacífico Sul, sendo elas: Taiti (17오, 150W) e Darwin (12오, 130ㅌ) (ACEITUNO, 1992).

\footnotetext{
${ }^{3}$ Mais informações podem ser obtidas em <http://www.esrl.noaa.gov/psd/enso/misc/hxsoi.html> acessado em 23/11/2014.
} 
O IOS assume valores positivos quando a pressão em Taiti é maior do que sua média climatológica (situação caracterizada por anomalias positivas) e a pressão em Darwin é menor do que sua média climatológica (situação caracterizada por anomalias negativas), contribuindo para a intensificação dos sistemas atmosféricos semipermanentes, respectivamente, a leste e a oeste do Pacífico Sul, tal como indicaram Ropelewski e Jones (1987). O IOS é negativo quando a pressão em Taiti é menor do que a média (gerando anomalias negativas nesta região) e, ao mesmo tempo, a pressão em Darwin é maior do que a média (gerando anomalias positivas), contribuindo para o enfraquecimento dos sistemas atmosféricos semipermanentes a leste e a oeste do Pacífico Sul.

No primeiro caso, as diferenças de anomalias de pressão entre as duas regiões sempre será positiva, enquanto que no segundo caso a diferença sempre será negativa. Valores negativos e positivos de IOS correspondem, portanto, respectivamente a episódios de El Niño (EN) e La Niña (LN) (ACEITUNO, 1992).

Os trabalhos de Bjerknes $(1966,1969)$ relacionados ao entendimento dos mecanismos físicos responsáveis pelas associações climáticas em larga escala contribuíram para mostrar que as anomalias de TSM observadas ao longo do Equador (regiões centro e leste do Pacífico), entre os meses de novembro de 1957 e fevereiro de 1958, foram acompanhadas pelo aumento da intensidade dos ventos de oeste em latitudes médias, a leste do Pacífico Norte. Estes trabalhos permitiram ainda sugerir que anomalias de temperatura da superfície do oceano Pacífico equatorial intensificaria a circulação de Hadley.

O detalhamento da variabilidade espaço-temporal da precipitação global em relação a episódios ENOS foi feito por Ropelewski e Halpert (1987), cujos resultados mostram a identificação de várias áreas do globo com variação no padrão climático de precipitação durante os episódios considerados.

$\mathrm{Na}$ AS, os autores, com o auxílio da análise de modos harmônicos, identificaram duas áreas cuja precipitação relaciona-se aos episódios EN, sendo elas o norte da AS, que inclui parte do norte do Brasil, Guiana Francesa, Suriname, Guiana e Venezuela, e o sudeste da AS, composto pela região sul do Brasil, Uruguai e partes da região nordeste da Argentina.

Na região norte da AS, verificaram a ocorrência de anomalias negativas de precipitação em 16 dos 17 episódios de EN analisados ( 94\%). Este estudo corroborou os resultados encontrados por Hastenrath e Heller (1977), que também encontraram relações negativas entre episódios de EN e a ocorrência de chuva no nordeste do Brasil. Para a região sudeste da AS, Ropelewski e Halpert (1987) observaram aumento de precipitação em 14 episódios de EN dentre os 16 analisados ( $88 \%$ ).

A fim de investigar os impactos dos eventos ENOS na precipitação mensal do sul do Brasil, Grimm et al. (1998) verificaram que as anomalias máximas positivas de precipitação ocorrem na primavera do ano de EN, com máximo em novembro, seguidas de forte enfraquecimento, e até mesmo da inversão do sinal da anomalia, entre dezembro e janeiro, diferentemente do que foi sugerido em Ropelewski e Halpert (1987), cujos estudos encontraram anomalias intensas e positivas de precipitação na estação de verão, durante os meses de novembro do ano de EN a fevereiro do ano seguinte.

De maneira geral, os impactos climáticos da precipitação na AS atribuídos a eventos EN caracterizam-se pelo aumento da precipitação no litoral do Equador e norte do Peru devido 
ao enfraquecimento da Alta do Pacífico Sul concomitantemente ao enfraquecimento dos ventos alíseos (DIAZ e KILADIS, 1992), pela diminuição da precipitação sobre as regiões norte-nordeste da AS devido ao deslocamento zonal da célula de Walker e ao aumento da subsidência sobre a região (GRIMM et al., 2003) e pelo aumento da precipitação na região sudeste da AS devido à intensificação do Jato Subtropical (JS) de altos níveis (GRIMM et al., 2003).

A intensificação do JS no sudeste da AS propicia a intensificação da convergência em baixos níveis, também identificada em estudos sobre a propagação de ondas de Rossby associada ao aquecimento anômalo no Pacífico Equatorial, situação observada em anos de EN, tal como discutido em Wallace e Gutzler (1981), Karoly (1989) e Ambrizzi (2003).

McPhaden (2002) identificou as localidades do globo que têm seus padrões de temperatura do ar e precipitação significativamente associados a episódios ENOS, como indicado na Figura 01.
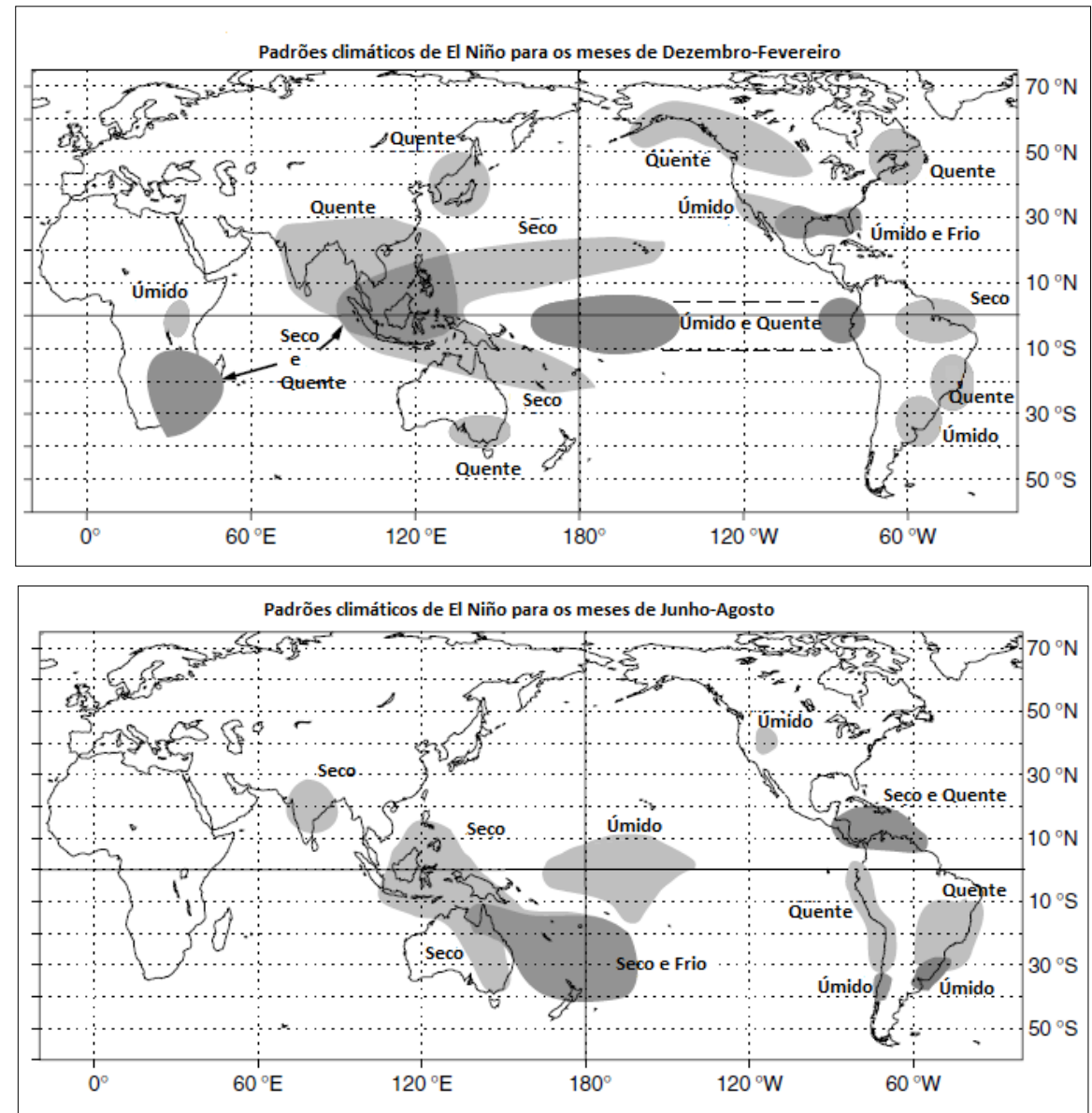

B

FIGURA 01: Diagrama esquemático, baseado nos trabalhos de Ropelewski e Halpert (1987) e Halpert e Ropelewski (1992), mostrando as anomalias de temperatura do ar e precipitação associados à ocorrência de eventos EN para os meses de (A) dezembro a fevereiro e (B) junho a agosto (b).

Fonte: McPhaden (2002), modificado. 
$\mathrm{Na}$ AS, durante episódios EN, verificam-se anomalias negativas e positivas de precipitação durante o verão, respectivamente, nas regiões norte e sudeste do continente. Em especial, o EN de 1997-1998 acarretou enormes impactos sócio-econômicos distribuídos globalmente. Dentre eles pode-se citar chuvas torrenciais e enchentes em partes da Califórnia, África Oriental e Chile, secas em Papua Nova Guiné, América Central e nordeste do Brasil (MCPHADEN, 1999). Incêndios ocorridos na Indonésia devido às condições climáticas mais secas e quentes que o normal produziram fumaça tóxica responsável por ocasionar problemas respiratórios generalizados, tal como mencionado por McPhaden (1999; 2002).

O diagnóstico de ocorrência (início e final) dos episódios ENOS é frequentemente estabelecido por meio de índices calculados com base em variáveis atmosféricas e oceânicas, tais como o IOS, o Multivariate ENSO Index (MEI) (WOLTER; TIMLIN, 1993) e a própria TSM das regiões de Niño (RASMUNSSON e CARPENTER, 1983; TRENBERTH, 1997).

Um dos critérios possíveis, para determinar a ocorrência de eventos ENOS, baseia-se na presença de valor absoluto da anomalia de TSM igual ou superior a 0,5으 persistentes por um período igual ou superior a cinco meses na região de Niño 3.4 do Pacífico Equatorial (SMITH et al., 2008). Kiladis e Loon (1988) utilizaram outra metodologia de classificação baseada no IOS, conjuntamente com anomalias de TSM ocorridas no Pacífico equatorial leste.

Para estes autores, os episódios de EN seriam definidos por anomalias positivas de TSM maiores ou iguais a 0,5 ㅇ $\mathrm{C}$ observadas por no mínimo três meses consecutivos, sendo que o IOS deveria apresentar concomitantemente valores inferiores a $-1,0$. Bjerknes (1969) observou que as anomalias de TSM sinalizadoras de eventos de EN também são acompanhadas pelo enfraquecimento dos ventos de leste, no Pacífico equatorial e pela diminuição da ressurgência oceânica na costa oeste da AS.

As áreas oceânicas comumente utilizadas para o monitoramento de anomalias de TSM no Oceano Pacífico Equatorial são conhecidas como regiões de Niño e foram classificadas de acordo com a distância em relação à costa oeste da AS, sendo chamadas de Niño 1+2, Niño 3, Niño 3.4 e Niño 4, dispostas na área circunscrita pelos paralelos $50 \mathrm{~N}$ e $50 \mathrm{~S}$ e pelos meridianos 80 ㅇ O e 160ㄴ L. A primeira região Niño 1+2 encontra-se mais próxima à costa oeste da AS, sendo que a região de Niño 4 é a mais afastada da costa, tal como indicado na Figura 02.

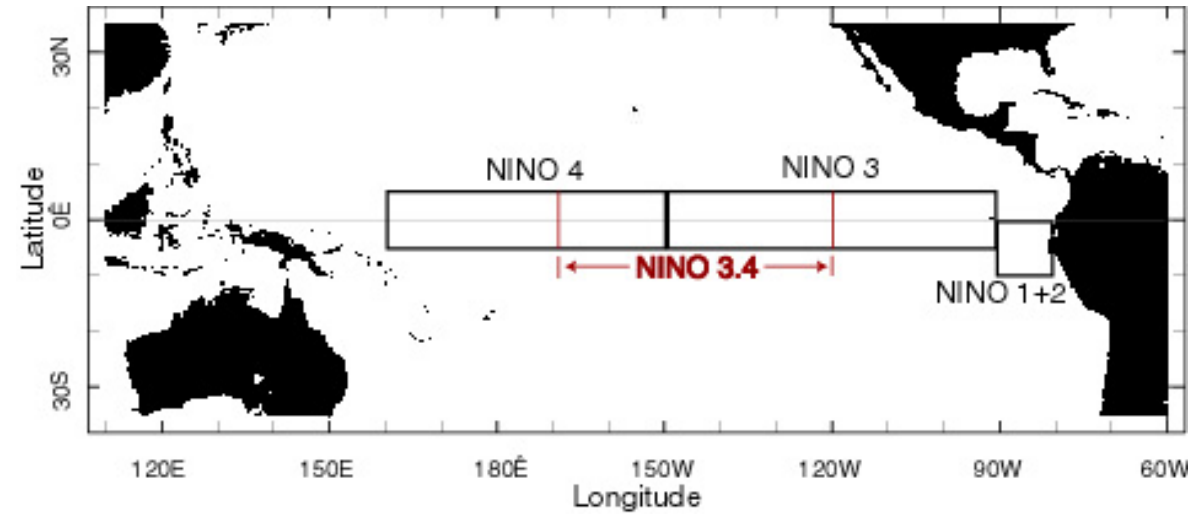

FIGURA 02: Localização das regiões de Niño no Oceano Pacífico.

Fonte: The International Research Institute for Climate and Society (IRI), (2014). 
Além da TSM das regiões de Niño, o índice $\mathrm{MEI}^{4}$ é outro parâmetro que auxilia a identificação de eventos de aquecimento e resfriamento anômalos das águas do Pacífico tropical. Seu valor advém da aplicação de análise multivariada (componentes principais) às seguintes variáveis: pressão atmosférica ao nível do mar, componentes zonal e meridional do vento em superfície, temperatura da superfície do oceano, temperatura do ar e a fração total de nuvens em áreas específicas do Pacífico.

O MEI é obtido a partir da primeira componente principal não rotacionada considerando todos os seis campos observados (WOLTER e TIMLIN, 1998). Valores positivos (negativos) do $\mathrm{MEI}$ sinalizam aquecimento (resfriamento) anômalo das águas do Pacífico Equatorial centroleste e eventualmente o início de um evento EN, tal como indicado na Figura 03.

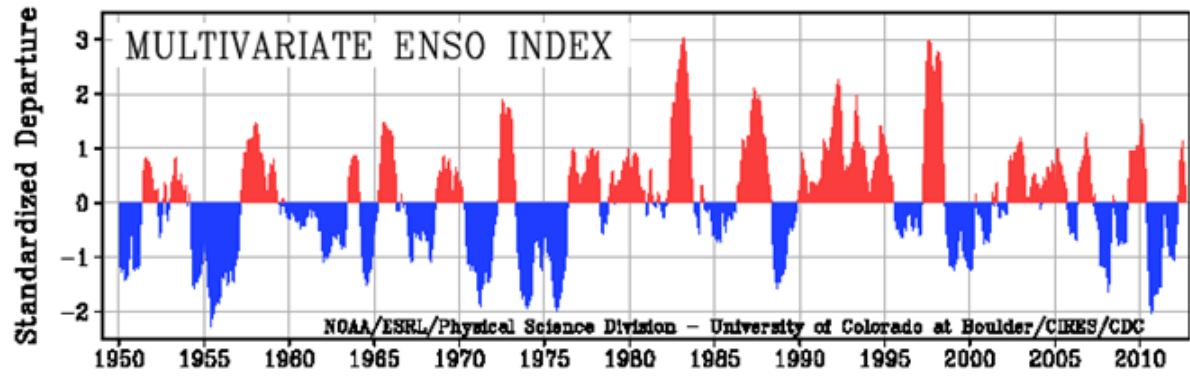

FIGURA 03: Série mensal do índice ENSO MEI, de 1950 a outubro de 2012. As barras em azul representam a ocorrência da LN, enquanto que as barras em vermelho, a de EN. Fonte: Physical Sciences Division (PSD/NOAA), (2014).

Lopes (2006) encontrou relações entre anomalias de precipitação no Rio Grande do Sul, a TSM das regiões de Niño e o índice MEl, entre os anos de 1950 a 2002, para os bimestres outubro-novembro e novembro-dezembro. Este autor observou que eventos de resfriamento, associados às anomalias negativas de MEI e de TSM nas regiões de Niño, apresentaram relações mais significativas com a precipitação do estado do Rio Grande do Sul, em comparação aos eventos de aquecimento do Pacífico.

Estudos como os descritos acima demonstraram que o monitoramento da ocorrência de anomalias de TSM é fundamental para o aprofundamento da compreensão dos fenômenos climáticos, uma vez que quando presentes modulam o comportamento atmosférico com a geração e propagação de ondas atmosféricas, através da modificação dos campos de pressão.

Embora os resultados mostrados evidenciem várias associações entre as anomalias de TSM no Pacífico Equatorial e a precipitação em várias áreas do globo, não permitem identificar a persistência do sinal do Pacífico Equatorial na precipitação mensal da AS. A persistência de associação entre estas duas variáveis permite definir parâmetros de previsibilidade da precipitação em relação aos índices ENOS. Propõe-se, portanto, neste estudo avaliar os

4. Os valores mensais do índice MEI podem ser adquiridos no site http://www.esrl.noaa.gov/psd/enso/mei/mei.html. 
resultados da associação entre a TSM das regiões de Niño, os índices que caracterizam o ENOS e a precipitação na AS, considerando-se a defasagem temporal entre as variáveis.

\section{MATERIAL E MÉTODO}

Os dados de precipitação usados neste estudo foram compilados por Liebmann e Allured (2005) e encontram-se disponíveis para a AS. O período estudado foi definido entre 1978 a 2005. Os dados de precipitação estão disponibilizados ${ }^{5}$ na escala temporal diária, tendo sido posteriormente transformada para a escala temporal mensal e resolução espacial de um grau. Além da TSM observada nas regiões de Niño 1+2, Niño 3, Niño 3.4 e Niño 4, os índices climáticos MEI e IOS foram usados para a verificação do padrão de correlação linear com a precipitação observada na AS. Os índices climáticos foram obtidos do Climate Prediction Center (CPC), do National Oceanic and Atmospheric Administration (NOAA) ${ }^{6}$, na escala mensal, para o período de 1978 a 2005.

Neste estudo, a associação entre a TSM das regiões de Niño, os índices IOS e MEI e a precipitação mensal observada na AS é definida pelo cálculo de correlação linear simples, com e sem defasagem temporal. No caso da defasagem, optamos por deslocar a série temporal da precipitação à frente das séries temporais das variáveis que caracterizam o ENOS, para permitir a avaliação de sua previsibilidade em função de eventos ENOS. O início da série temporal das variáveis de TSM, IOS e MEI foi mantido sempre como o mês de janeiro de 1978, enquanto que a precipitação mensal inicial foi deslocada à frente, de janeiro a outubro de 1978.

O cálculo do coeficiente de correlação linear de Pearson $(r)$ entre duas variáveis quaisquer, $x$ e y, pode ser descrito, como mencionado em Wilks (2006), por:

$$
r=\frac{\sum_{i=1}^{N}\left(x_{i}-\bar{x}\right)\left(y_{i}-\bar{y}\right)}{\sigma_{x} \sigma_{y}}
$$

em que ${ }^{x_{i}}$ e $y_{i}$ indicam as duas variáveis observadas em cada passo de tempo i; $\bar{x}$ e $\bar{y}$, a média aritmética de cada série temporal; ${ }^{\sigma_{x}}$ e $\sigma_{y}$ são, respectivamente, o desvio padrão das séries temporais de $x$ e $y$.

O cálculo do coeficiente de correlação linear com defasagem temporal foi realizado pelo atraso mensal da TSM, do MEI e IOS em relação aos dados de precipitação, de forma a permitir resultados que pudessem sugerir a influência dos índices de ENOS na precipitação

5. Disponíveis em: <www.esrl.noaa.gov/psd/data/gridded/data.south_america_precip.html> Acessado em 09/02/2015.

6. Disponível em: http://www.esrl.noaa.gov/psd/data/climateindices/ 
da AS. O cálculo matemático da correlação linear com defasagem temporal entre a precipitação e os índices de ENOS pode ser expresso da seguinte forma:

$$
\begin{gathered}
\boldsymbol{r}_{i, p}=\frac{\sum_{i=1}^{N}\left(x_{i}-\bar{x}\right)\left(y_{i+p}-\bar{y}\right)}{\sigma_{x} \sigma_{y}}, \\
\boldsymbol{p}=[0,9] \mathbf{e} \mathrm{i}=[1,9]
\end{gathered}
$$

em que $p$ é o índice que indica o deslocamento temporal em relação a $i$. Os demais termos desta equação têm a mesma interpretação que na equação anterior.

O ciclo sazonal de cada uma das variáveis foi removido anteriormente à realização do cálculo da correlação linear. A remoção do ciclo sazonal de uma série temporal pode ser feita através da remoção da média climatológica de cada mês do valor mensal observado. Desta forma, obtém-se a anomalia da variável considerada, que pode ser escrita segundo Wilks (2006), como:

$$
y_{i, j}^{\prime}=y_{i, j}-\bar{y}_{j}
$$

em que o apóstrofo indica o desvio em relação à média; a barra acima da variável, a média para o período, $i$ e $j$ são índices temporais que indicam os contadores de anos e meses, respectivamente.

A significância estatística relativa ao cálculo do coeficiente de correlação linear foi avaliada com a aplicação do teste $t$-Student (COSTA NETO, 1977).

As localidades da AS que apresentaram as maiores correlações entre a TSM das regiões de Niño, índices MEI, IOS e a precipitação no norte (PNAS) e sul (PSAS) estão listadas na Tabela 01 e indicadas nos mapas das Figuras 05 a 10 pelos retângulos amarelos e pretos, respectivamente. Foi realizada a média espacial da correlação nestas localidades, a fim de se observar a persistência do sinal de correlação para uma defasagem temporal de 0 a 9 meses (janeiro a outubro).

TABELA 01: Localidades na América do Sul que apresentaram os maiores valores de correlação linear entre a TSM das regiões de Niño, os índices MEI e IOS e a precipitação, para o período de 1978 a 2005

\begin{tabular}{rcc}
\hline & Localidades \\
\hline \multicolumn{1}{c}{ Índices } & PNAS & PSAS \\
\hline Niño $1+2$ & $60^{\circ} \mathrm{O} 50^{\circ} \mathrm{O} ; 5^{\circ} \mathrm{S} 2^{\circ} \mathrm{N}$ & $60^{\circ} \mathrm{O} 50^{\circ} \mathrm{O} ; 30^{\circ} \mathrm{S} 22^{\circ} \mathrm{S}$ \\
Niño 3 & $60^{\circ} \mathrm{O} 50^{\circ} \mathrm{O} ; 5^{\circ} \mathrm{S} 2^{\circ} \mathrm{N}$ & $58^{\circ} \mathrm{O} 50^{\circ} \mathrm{O} ; 32^{\circ} \mathrm{S} 25^{\circ} \mathrm{S}$ \\
Niño 3.4 & $60^{\circ} \mathrm{O} 50^{\circ} \mathrm{O} ; 5^{\circ} \mathrm{S} 2^{\circ} \mathrm{N}$ & $60^{\circ} \mathrm{O} 51^{\circ} \mathrm{O} ; 31^{\circ} \mathrm{S} 22^{\circ} \mathrm{S}$ \\
Niño 4 & $60^{\circ} \mathrm{O} 54^{\circ} \mathrm{O} ; 5^{\circ} \mathrm{S} 2^{\circ} \mathrm{N}$ & $60^{\circ} \mathrm{O} 54^{\circ} \mathrm{O} ; 31^{\circ} \mathrm{S} 22^{\circ} \mathrm{S}$ \\
MEI & $60^{\circ} \mathrm{O} 50^{\circ} \mathrm{O} ; 5^{\circ} \mathrm{S} 2^{\circ} \mathrm{N}$ & $58^{\circ} \mathrm{O} 52^{\circ} \mathrm{O} ; 32^{\circ} \mathrm{S} 25^{\circ} \mathrm{S}$ \\
IOS & $60^{\circ} \mathrm{O} 53^{\circ} \mathrm{O} ; 5^{\circ} \mathrm{S} 2^{\circ} \mathrm{N}$ & $58^{\circ} \mathrm{O} 52^{\circ} \mathrm{O} ; 32^{\circ} \mathrm{S} 29^{\circ} \mathrm{S}$ \\
\hline
\end{tabular}

Fonte: SILVA, E.R.L.D.G (2014). 
Para verificar o comportamento médio da precipitação na AS em períodos de EN, LN e anos neutros, todos os meses da série temporal considerada (1978-2005) foram classificados de acordo com o Índice Oceânico de Niño, Oceanic Niño Index (ONI), conforme indicado por Smith et al. (2008). Assim, um episódio quente ou frio do Pacífico Equatorial foi considerado para valores absolutos de $\mathrm{ONI}$ superiores a $0,5^{\circ} \mathrm{C}$, com persistência maior ou igual a cinco meses consecutivos. O ONI é igual à média trimestral da anomalia de TSM na região de Niño 3.4 (SMITH et al., 2008). Os períodos analisados e utilizados para a construção das médias de precipitação estão identificados na Tabela 02.

TABELA 02: Eventos ENOS e respectivos meses selecionados para a elaboração dos padrões médios de precipitação na AS.

\begin{tabular}{c|c|c}
\hline El Niño & La Niña & Neutros \\
\hline mai/1982 - jun/1983 & out/1984 - set/1985 & mar/1978 - abr/1979 \\
mai/1991 - jun/1992 & mai/1988 - mai/1989 & jan/1990 - mai/1991 \\
mai/1997 - abr/1998 & jul/1998 - jul/1999 & mar/2003 - jun/ 2004 \\
\hline
\end{tabular}

Fonte: SILVA, E.R.L.D.G (2014).

O início da série temporal de TSM das Figuras 05 a 10 foi definido como o mês de janeiro de 1978. Os valores apresentam significância estatística superiores a 99\% (teste t-Student); a informação pode ser omitida das Figuras 05 a 10.

A leitura dos dados e o cálculo de médias mensais foram feitos parcialmente em linguagem computacional Fortran. Os cálculos de correlação linear, com e sem defasagem temporal, a construção dos mapas e gráficos foram obtidos com o uso do software livre Grid Analysis and Display System (GrADS).

\section{RESULTADOS E DISCUSSÃO}

De forma geral, a TSM de todas as áreas do Oceano Pacífico Equatorial que caracterizam a ocorrência de ENSO, Niño 1+2, Niño 3, Niño 3.4 e Niño 4, além do índice climático MEI, apresentam, respectivamente, correlação linear negativa e positiva com a precipitação mensal observada nas regiões norte e sudeste da AS, tal como observado nas Figuras 04 a 09. A precipitação registrada nestas regiões foi chamada de precipitação ao norte e sul da AS, com os acrônimos PNAS e PSAS, respectivamente. As áreas associadas à PNAS e PSAS apresentam pequenas diferenças de acordo com o índice oceânico considerado, como já indicadas na Tabela 01.

O gráfico da Figura 4a exibe a correlação com defasagem temporal de até nove meses entre a TSM das regiões de Niño e a precipitação no norte e sul da AS. Nota-se que quanto maior a defasagem temporal, menor a correlação entre as variáveis. Valores positivos de correlação superiores a 0,2 são observados entre a TSM das regiões de Niño e a precipitação da região sudeste da AS, para uma defasagem temporal de até dois meses (janeiro a março).

De modo distinto, a precipitação ao norte da AS apresenta valores negativos de correlação, inferiores a -0,3, com a TSM das regiões de Niño, e persistentes por até três meses (janeiro a junho). No caso da TSM na região do Niño $1+2$, a persistência chega a ser de até cinco meses. 
O índice MEI apresenta correlação linear positiva com a precipitação ao sudeste da AS, com valores superiores a 0,2 para defasagens de até dois meses (janeiro a março) e, negativa, com valores inferiores a - 0,3 , com a precipitação do norte da AS, entre janeiro e abril (Figura 4b). Estes resultados são semelhantes aos obtidos com as TSMs das regiões de Niño.

Os valores de correlação calculados com base no IOS (Figura 4b) indicam sinais contrários aos obtidos para os demais índices oceânicos uma vez que, para este índice, valores positivos e negativos indicam, respectivamente, eventos LN e EN, assim como apresentado na Figura 4b. O índice MEl apresenta valores de correlação com a precipitação do sudeste da AS sempre mais intensos do que o IOS.

Além do sinal contrário de correlação linear verificado entre a precipitação registrada nas regiões norte e sudeste da AS, observa-se diferença de intensidade do valor de correlação. $A$ precipitação mensal do norte da AS apresenta valores absolutos de correlação com os índices climáticos relativos ao ENOS, em média, mais altos do que a precipitação do sudeste da AS (Figura 4a-b).

Enquanto os valores mais intensos de correlação na região norte da AS variam entre $-0,4$ e 0,3 , para a região sudeste da AS, os valores mais altos de correlação variam entre 0,2 e 0,3. Há um decréscimo quase linear do valor da correlação entre os índices que caracterizam o ENOS e a precipitação no norte e sudeste da AS conforme a defasagem temporal aumenta (Figura 4).

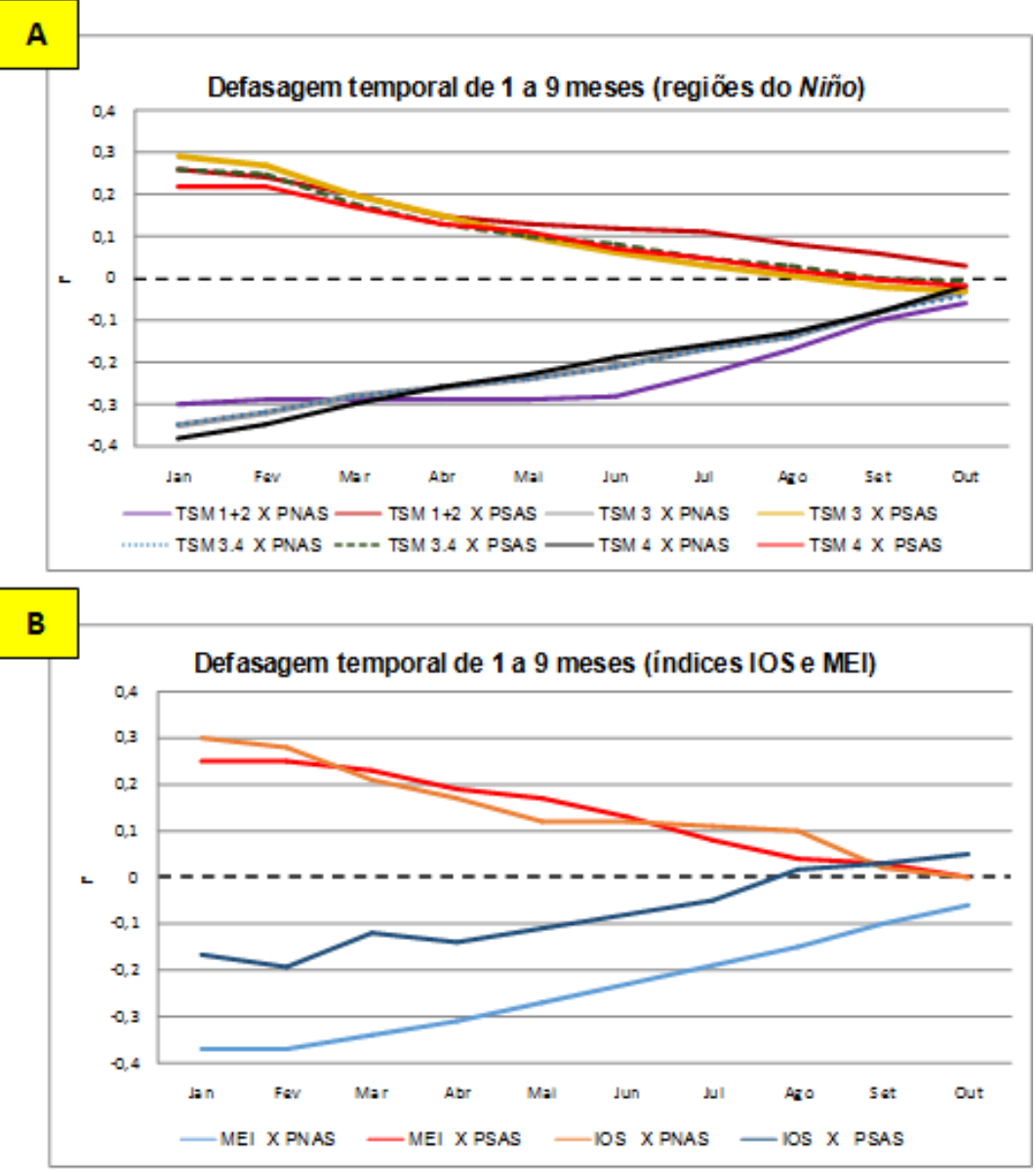


FIGURA 04: Correlação linear entre a precipitação no norte (PNAS) e sudeste (PSAS) da AS e (A) a TSM das regiões de Niño e (B) os índices MEl e IOS, para defasagem temporal de até nove meses, no período de 1978 a 2005. Fonte: SILVA, E.R.L.D.G (2014).

\section{- Região de Niño 1+2}

O padrão espacial de correlação entre a TSM da região de Niño 1+2 e a precipitação da AS apresenta valores positivos superiores $a+0,3$, com persistência de até três meses (até abril) para o sul do Brasil (sul do Paraná e Santa Catarina), Paraguai e nordeste da Argentina. Outra região que apresenta valores relativamente altos de correlação com a TSM da região do Niño $1+2$, porém negativos, é a porção centro-norte do Pará e o nordeste do Brasil com valores inferiores a -0,3 e persistência de até três meses (Figura 05).

A precipitação mensal na costa oeste do Equador apresenta correlação alta e positiva com a TSM da região de Niño 1+2, com valores superiores a 0,6, para defasagens de até dois meses (Figura 05). A anomalia de precipitação nesta área está associada ao deslocamento zonal dos movimentos ascendentes da célula de Walker em períodos de anomalias positivas de TSM no Pacífico, tal como discutem Bjerknes (1969) e vários outros autores que estudaram posteriormente os processos físico-dinâmicos associados ao fenômeno, tais como Diaz e Kiladis (1992), Grimm et al. (2003) e Grimm (2009).

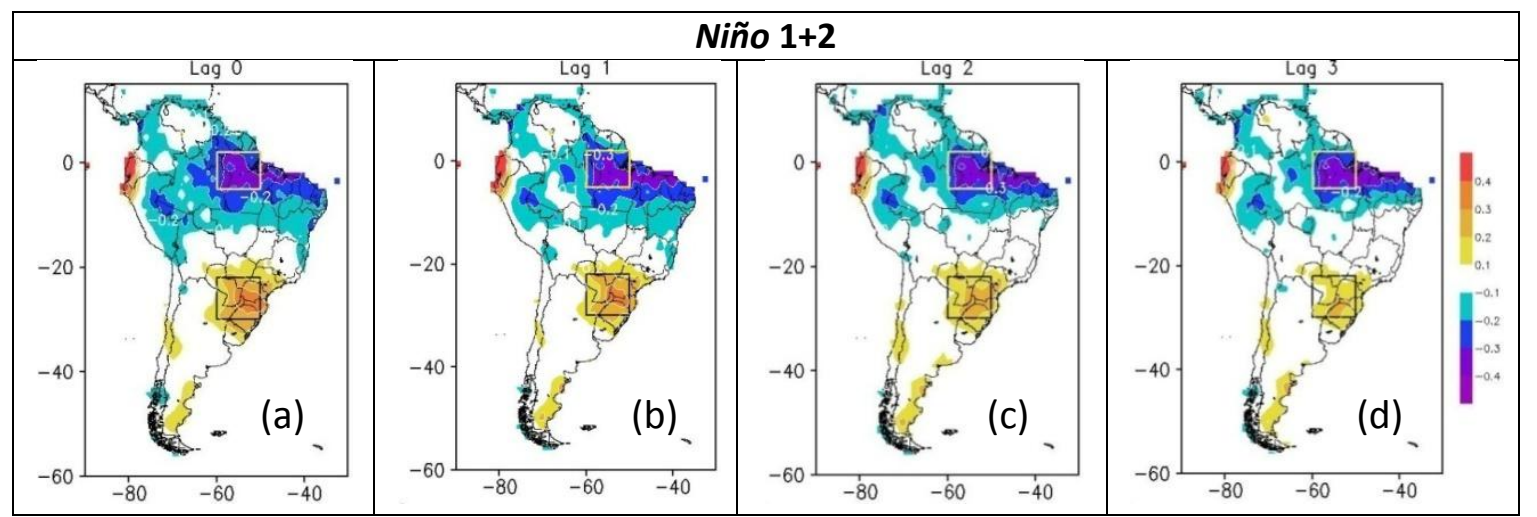

FIGURA 05: Correlação linear simples entre a TSM da região do Niño 1+2 e a precipitação mensal da

AS, de 1978 a 2005, para distintos intervalos de defasagem temporal entre as variáveis correlacionadas. (a) correlação sem defasagem temporal; correlação com defasagem temporal de (b) 1 (c) 2 e (d) 3 meses.

Fonte: SILVA, E.R.L.D.G (2014).

\section{- Região de Niño 3}

Considerando-se a região do Niño 3 (Figura 06), verifica-se que os padrões espaciais de correlação da precipitação da AS com a TSM da região de Niño 3 são bastante parecidos aos padrões relativos à TSM da região de Niño 1+2 (Figura 05), ocorrendo pequenas diferenças com relação à localização e persistência do sinal mais intenso.

Novamente, as regiões que apresentam maiores valores absolutos de correlação são o sul do Brasil, com valores maiores no Rio Grande do Sul, nordeste da Argentina e Paraguai, e norte e nordeste do Brasil. A TSM da região de Niño 3 apresenta pouca associação com a 
precipitação do sul do Brasil e áreas adjacentes para defasagens superiores a dois meses, assim como a TSM da região do Niño $1+2$.

O setor oeste da Colômbia apresenta correlações negativas e relativamente intensas ( $r<-$ $0,3)$ da precipitação com a TSM da região de Niño 3, tanto para o caso sem intervalo temporal (Figura 06a) como para as defasagens de um a três meses (Figuras 06b-d), o que não ocorre no caso da TSM da região de Niño $1+2$.

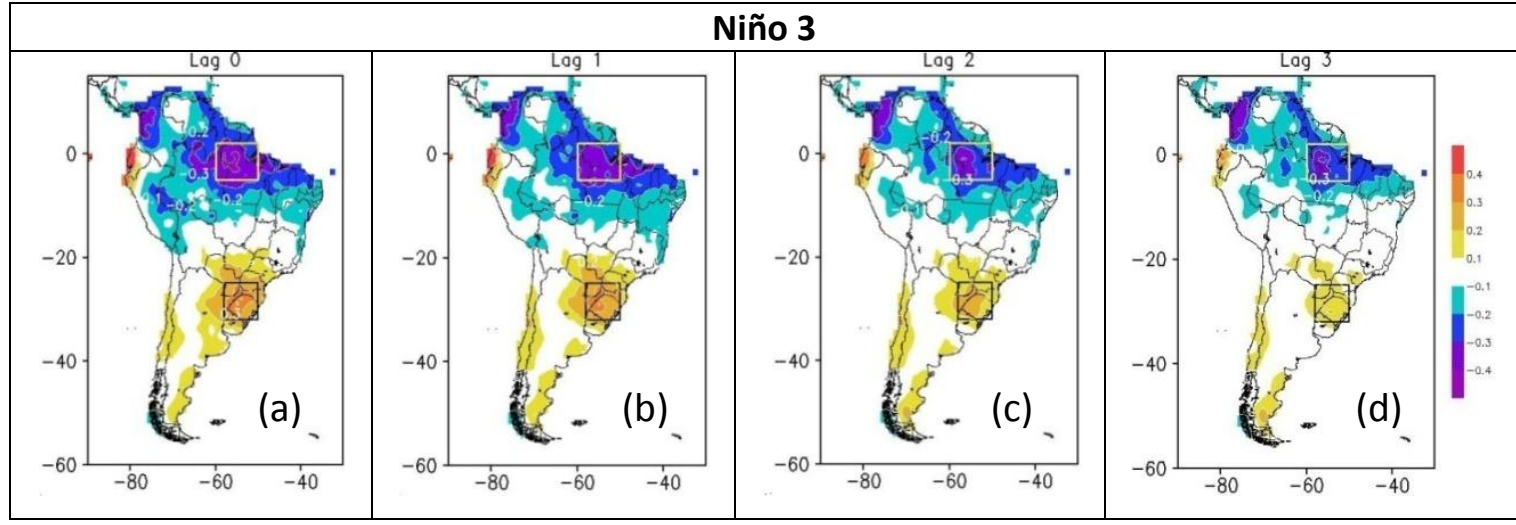

FIGURA 06: Correlação linear simples entre a TSM da região do Niño 3 e a precipitação mensal da

AS, de 1978 a 2005, para distintos intervalos de defasagem temporal entre as variáveis correlacionadas. (a) correlação sem defasagem temporal; correlação com defasagem temporal de (b) 1 (c) 2 e (d) 3 meses.

Fonte: SILVA, E.R.L.D.G (2014).

\section{- Região de Niño 3.4}

A TSM da região de Niño 3.4 apresenta padrões espaciais de correlação com a precipitação bastante parecidos aos padrões relativos à TSM das regiões de Niño 1+2 e 3. A persistência e a intensidade do sinal de correlação entre a TSM e a precipitação do setor oeste da Colômbia são maiores se comparadas aos valores associados às regiões de Niño 1+2 e Niño 3 , com valores inferiores a $-0,3$, para a região norte da $A S$, e valores superiores a $+0,2$ para a região sudeste da AS, para defasagens de até três meses (Figura 07). A TSM da região de Niño 3.4 apresenta pouca associação linear com a precipitação do sudeste da AS e adjacências para defasagens superiores a dois meses, assim como a TSM da região do Niño $1+2$.

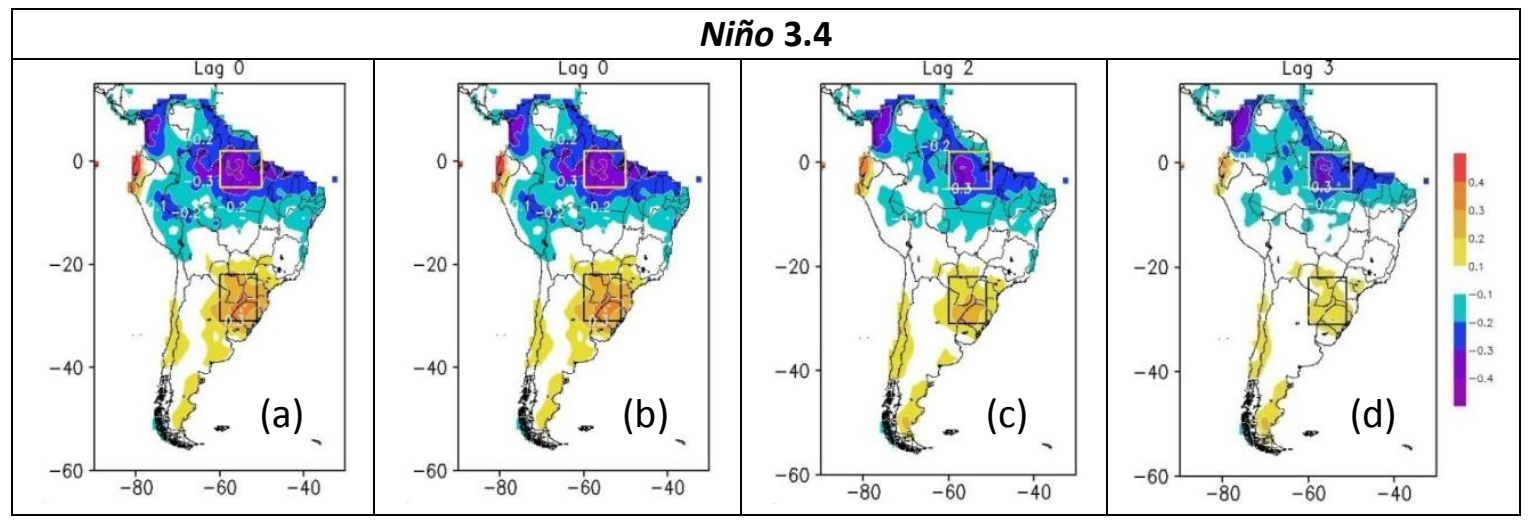

FIGURA 07: Correlação linear simples entre a TSM da região do Niño 3.4 e a precipitação mensal da AS, de 1978 a 2005, para distintos intervalos de defasagem temporal entre as variáveis 
correlacionadas. (a) correlação sem defasagem temporal; correlação com defasagem temporal de (b) 1 (c) 2 e (d) 3 meses.

Fonte: SILVA, E.R.L.D.G (2014).

\section{- Região de Niño 4}

A TSM da região de Niño 4 e a precipitação na AS apresentam correlação linear positiva no sudeste da AS, incluindo os estados do sul do Brasil, Uruguai e o extremo nordeste da Argentina (Figura 08). Há um pequeno sinal positivo de correlação entre a TSM da região do Niño 4 e a precipitação na costa do Equador.

Assim como para os padrões de correlação linear entre a precipitação e a TSM da região de Niño 3.4, a TSM da região de Niño 4 apresenta correlação negativa com a precipitação do setor oeste da Colômbia, com valores relativamente fortes $(-0,5<r<-0,4)$, permanecendo com valores similares para defasagens de até três meses.

A precipitação da região norte da AS está associada negativamente à TSM da região de Niño 4, com destaque para os estados brasileiros do Amazonas e Pará, que apresentam valores expressivos, inferiores a - 0,4. A precipitação de grande parte da região Norte do Brasil e parte do Nordeste apresentam valores negativos de correlação com a TSM da região do Niño 4 , sendo os maiores valores absolutos observados na região Norte $(-0,4<r<-0,3)$.

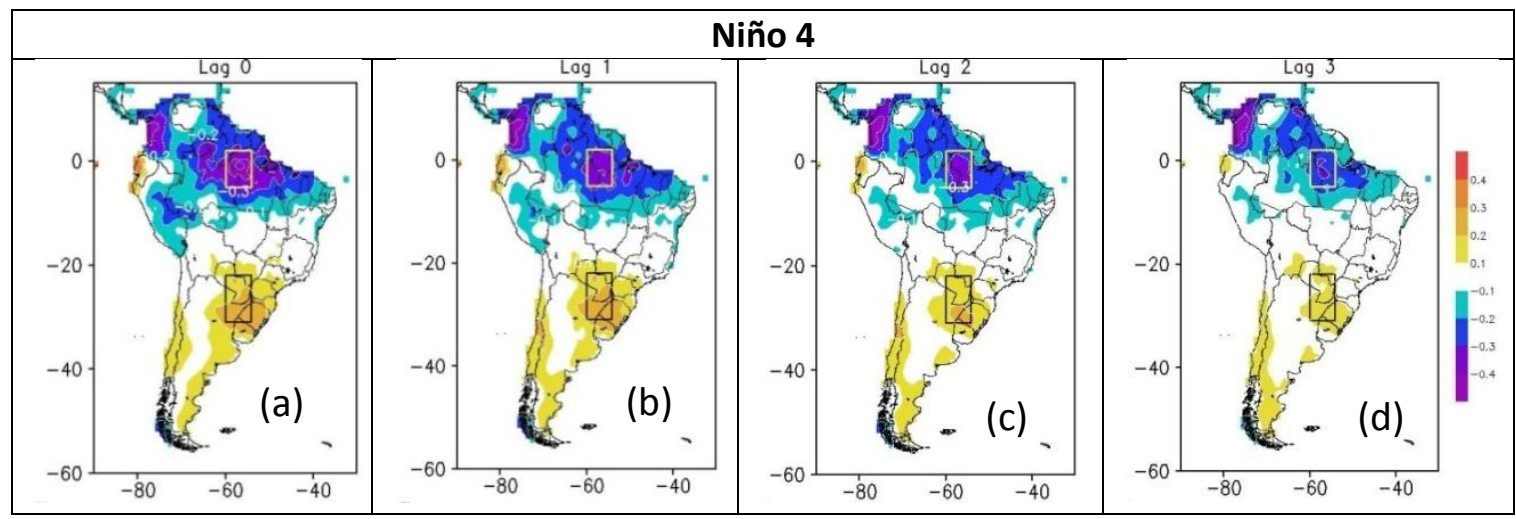

FIGURA 08: Correlação linear simples entre a TSM da região do Niño 4 e a precipitação mensal da

AS, de 1978 a 2005, para distintos intervalos de defasagem temporal entre as variáveis correlacionadas. (a) correlação sem defasagem temporal; correlação com defasagem temporal de (b) 1 (c) 2 e (d) 3 meses.

Fonte: SILVA, E.R.L.D.G (2014).

\section{- Multivariate ENSO Index}

Poucas diferenças entre os padrões espaciais de correlação linear são observadas quando considerados os diferentes indicadores climáticos de ENOS. Dentre todos os indicadores do Pacífico, o MEI (Figura 09) é o que provê a maior abrangência espacial dos valores absolutos mais altos de correlação linear (por vezes, superiores a 0,4 ) com a precipitação do norte da 
AS. No setor oeste da Colômbia, verificam-se valores altos, negativos e persistentes (até seis meses), com correlação linear absoluta superior a 0,4, da precipitação com o MEI.

O setor oeste do Equador, apesar de pequeno, apresenta altos valores positivos de correlação linear entre a precipitação e o $\operatorname{MEI}(+0,4 /+0,5)$, em especial para defasagens temporais de até dois meses (Figura 9a-c).

A precipitação do setor leste do estado do Amazonas, do centro norte do Pará, Maranhão e norte do Piauí, apresenta forte correlação negativa com o $\mathrm{MEI}$, com valores máximos variando entre $-0,5$ e - 0,3 . A precipitação do sudeste da AS apresenta correlação linear associada ao $\mathrm{MEI}$ mais baixa do que a precipitação da região norte, com valores máximos variando entre 0,2 e 0,3, para defasagens de até três meses (Figura 09).

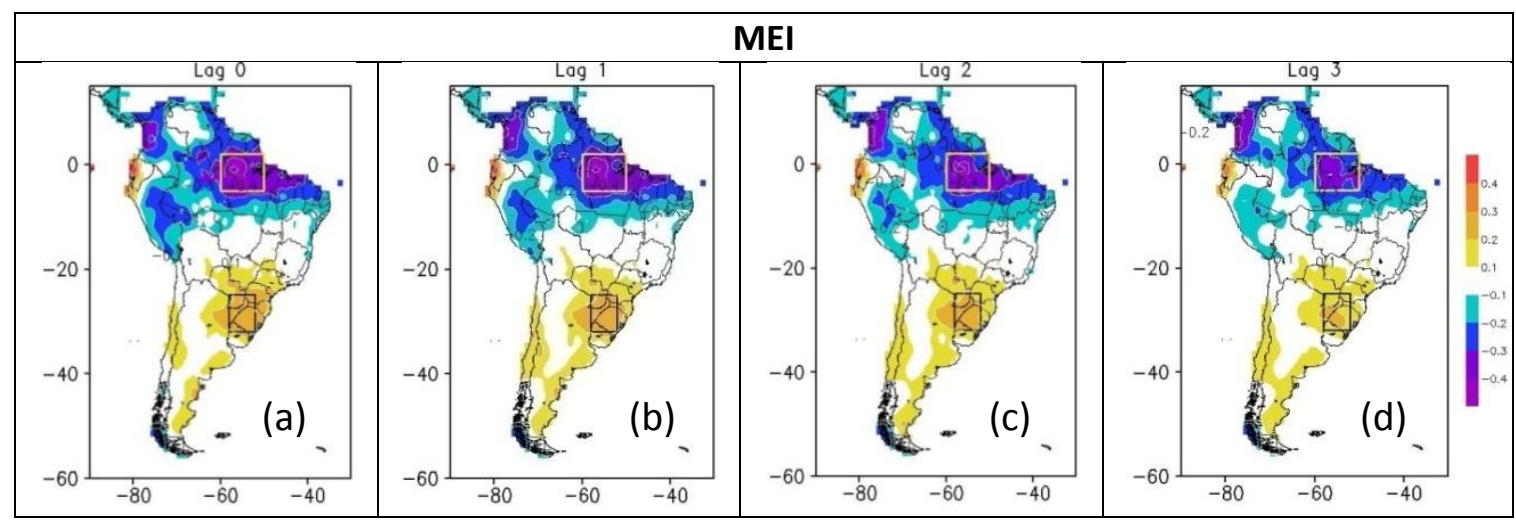

FIGURA 09: Correlação linear simples entre o MEl e a precipitação mensal da AS, de 1978 a 2005, para distintos intervalos de defasagem temporal entre as variáveis correlacionadas. (a) correlação sem defasagem temporal; correlação com defasagem temporal de (b) 1 (c) 2 e (d) 3 meses. Fonte: SILVA, E.R.L.D.G (2014).

\section{- Índice de Oscilação Sul}

Os maiores valores de correlação do IOS com a precipitação na região norte da AS variam entre 0,3 e 0,4, para defasagens de até dois meses (Figura 10), sobre o noroeste do Pará e setor oeste da Colômbia. A associação entre o sinal do IOS e a precipitação da Colômbia pode ser vista para defasagens de até seis meses entre as duas variáveis. A precipitação da região sudeste da AS apresenta sinal negativo de correlação com o IOS, com baixa significância estatística. O sinal da IOS no sudeste da AS é pouco persistente e, nas demais áreas, a correlação do IOS com a precipitação não é significativa.

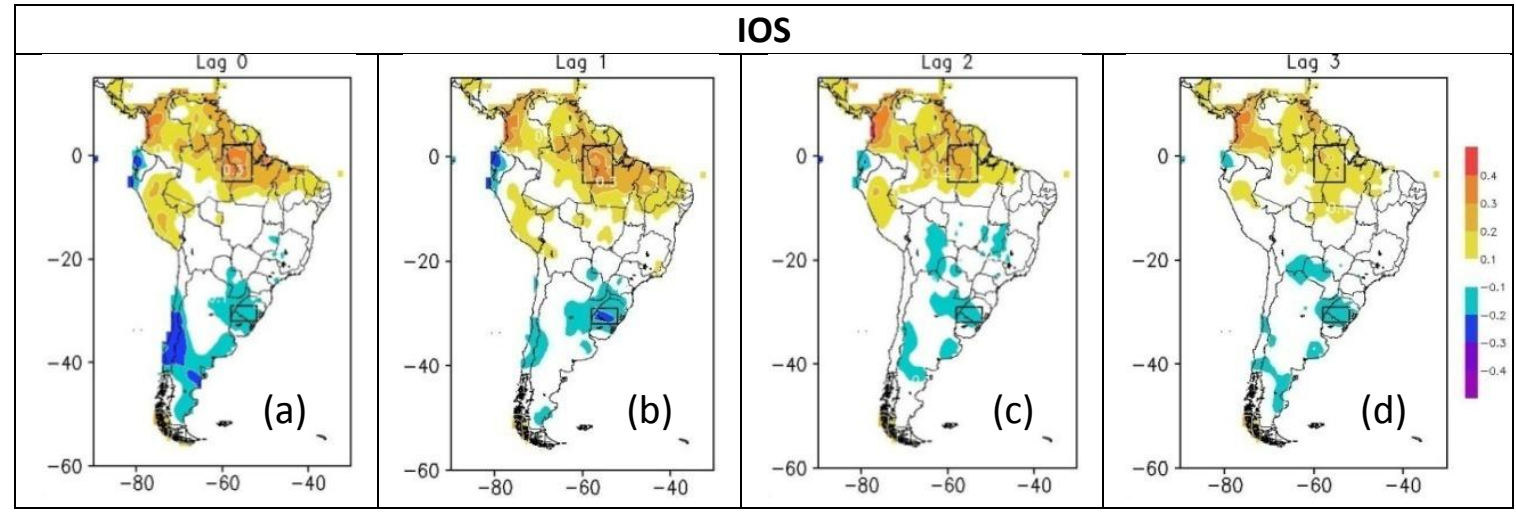


FIGURA 10: Correlação linear simples entre o IOS e a precipitação mensal da AS, de 1978 a 2005, para distintos intervalos de defasagem temporal entre as variáveis correlacionadas. (a) correlação sem defasagem temporal; correlação com defasagem temporal de (b) 1 (c) 2 e (d) 3 meses. Fonte: SILVA, E.R.L.D.G (2014).

\section{- Precipitação em anos de ENOS}

Os campos de anomalia média de precipitação para anos com eventos de EN e LN, no período de 1978 a 2005, indicam, na Figura 11, que a precipitação das regiões norte e sudeste da AS são as áreas mais associadas aos episódios de aquecimento e resfriamento do Pacífico Equatorial. Para os anos de EN (Figura 11a) selecionados neste estudo (Tabela 02), observam-se anomalias negativas de precipitação na região norte da AS e, positivas na região sudeste, com déficits e incrementos máximos que variam de 50 a $60 \mathrm{~mm}$ mês $^{-1}$ nas duas regiões.

Os maiores valores absolutos de déficit de precipitação ocorrem nos estados do Pará, Amapá, setor leste do Amazonas, norte do Maranhão e do Piauí. O déficit médio de precipitação no norte da AS, em anos de EN, no período considerado neste estudo, corresponde a aproximadamente $20 \%$ do valor da precipitação climatológica (Figura 11b) que é de aproximadamente 2500 a 3000 mm anuais (QUADRO et al., 1996).

Anomalias positivas de precipitação, superiores a $30 \mathrm{~mm} \mathrm{mês}^{-1}$, são encontradas na região Sul do Brasil, sudeste do Paraguai, extremo nordeste da Argentina e norte do Uruguai. Estes resultados são consistentes com os encontrados por Grimm et al. (1998). O incremento na precipitação no sudeste da AS, em anos de EN, corresponde a aproximadamente $30 \%$ do valor climatológico (Figura 11b) uma vez que a média anual varia entre 1250 e 2000 mm (QUADRO et al., 1996).

Nos casos de LN, o sinal de associação entre eventos ENOS e a precipitação na AS se mostra mais fraco do que em anos de EN, tanto no norte quanto no sudeste do continente. $O$ incremento máximo de precipitação na região norte da AS varia entre 40 e $50 \mathrm{~mm} \mathrm{mês}{ }^{-1}$ e o déficit máximo na região sudeste varia entre 20 e $30 \mathrm{~mm} \mathrm{mês}^{-1}$ (Figura 11c).

Para os anos neutros selecionados, não se observa, em geral, sinal significativo de anomalias de precipitação na AS (Figuras 11e, 11f). Estudos anteriores documentam o aumento e diminuição da precipitação, respectivamente, no sudeste e norte da AS quando da instalação de eventos de EN, tal como demonstram os trabalhos de Ropelewski e Halpert (1987), Grimm et al. (1998; 2000), Grimm (2003) e Coelho et al. (2002). 

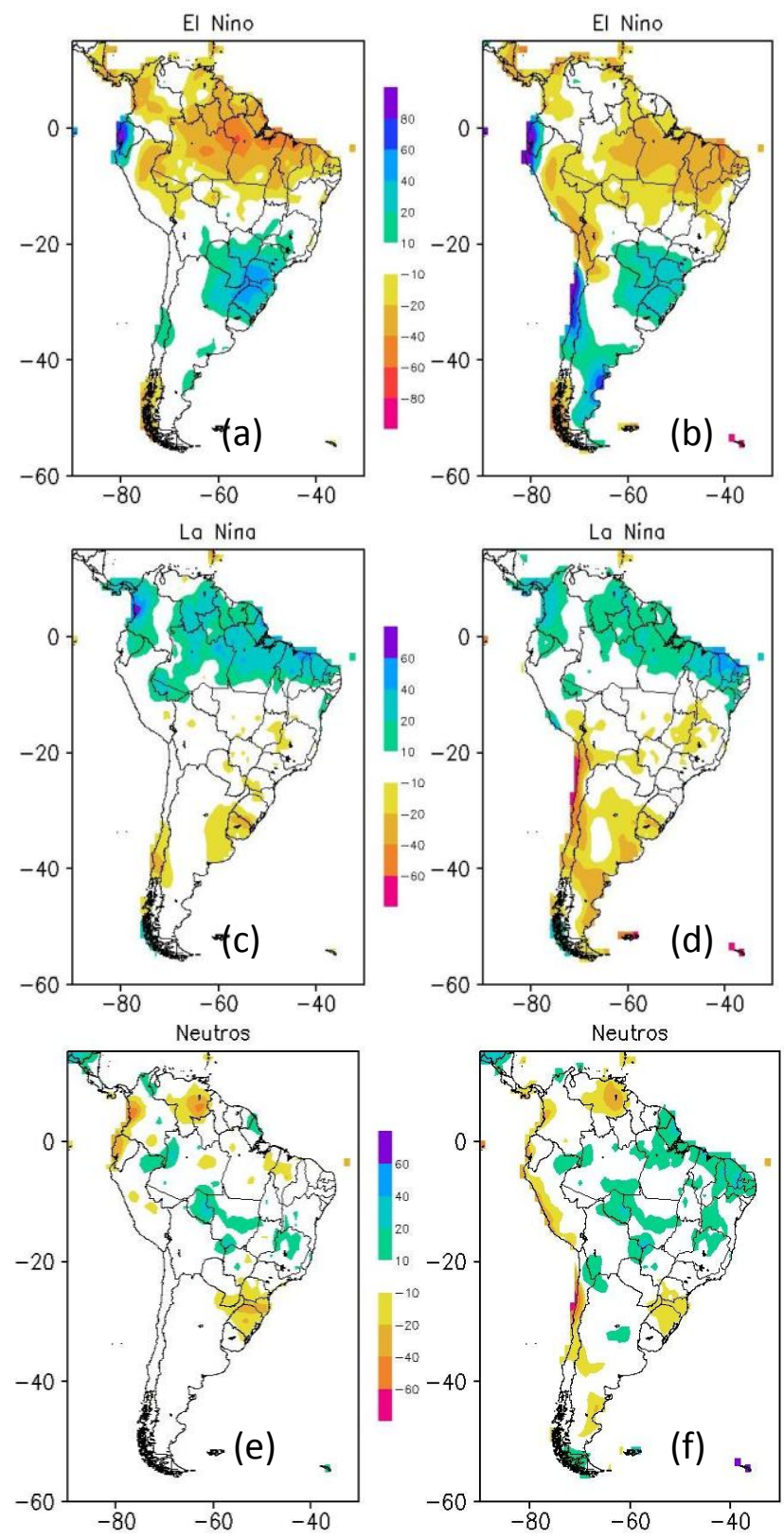

FIGURA 11: Anomalia absoluta da precipitação mensal $\left(\mathrm{mm}^{\mathrm{mês}}{ }^{-1}\right)$ na América do Sul para eventos (a) EN, (c) LN e (e) neutros. Anomalia relativa de precipitação climatológica (\%) para eventos (b) EN, (d) LN e (f) neutros, entre 1978 e 2005.

Fonte: SILVA, E.R.L.D.G (2014).

\section{CONCLUSÃO}

A análise da distribuição espacial da correlação linear entre índices climáticos que indicam a ocorrência de eventos ENOS e a precipitação sobre a AS, com e sem defasagem temporal, aponta as localidades que apresentam os maiores coeficientes. As regiões norte e sudeste do continente sulamericano, tal como indicam os estudos de Ropelewski e Halpert (1987), 
Grimm et al. (1998, 2000), Coelho et al. (2002), entre outros, apresentam, respectivamente, os maiores valores negativos e positivos (para o IOS os sinais se invertem) de correlação linear.

Com relação ao potencial de previsibilidade que cada índice climático (TSM nas regiões de Niño, MEI e IOS) carrega em relação à precipitação mensal nas regiões norte e sudeste da AS, observa-se que ele decai quase que linearmente com o aumento da defasagem temporal. Este resultado indica que a previsão da precipitação para os setores norte e sudeste da AS, eventualmente realizada a partir dos índices climáticos considerados, deve ter mais sucesso para os índices observados em meses antecedentes mais próximos daquele para o qual se deseja fazer a previsão.

Verifica-se ainda que os maiores valores de correlação linear, com e sem defasagem temporal, ocorrem para a precipitação observada na região norte da AS, o que pode estar associado à influência mais direta do deslocamento e intensificação do movimento de subsidência da célula de Walker, como comentam Walker (1969), Webster e Chang (1988) e McPhaden et al. (1998), que inibem o movimento ascendente na região.

A área da AS que apresenta correlações lineares significativas entre a precipitação mensal e os índices climáticos oceânicos, com valores absolutos superiores a 0,3 , é bem mais abrangente no norte da AS do que no sudeste, assim como também observaram Grimm et al. (1998, 2000), Coelho (2001), e Coelho et al. (1999, 2002).

Este aspecto é explicado em outros estudos pela forma mais direta de perturbação do campo atmosférico na região norte da AS, devido às mudanças ocorridas na circulação da célula de Walker que, em anos de EN apresenta um padrão anômalo de circulação troposférica, com anomalias negativas do movimento ascendente sobre a região nordeste do Brasil, leste da região amazônica e Atlântico equatorial (KOUSKY et al. 1984). A anomalia de precipitação na região sudeste da AS ocorre pela intensificação do JS em resposta à anomalia positiva de TSM na região do Pacífico Equatorial, como sugerem Grimm (1996) e Satyamurty et al. (1998).

Em geral, a análise dos padrões espaciais da correlação linear entre os índices climáticos e a precipitação mensal na AS permite perceber que as áreas potencialmente influenciadas pelo ENOS permanecem inalteradas em relação ao observado para cálculos sem defasagem temporal, mostrando, porém, a diminuição do valor de correlação com o aumento da defasagem temporal.

O MEl e a TSM das regiões de Niño 1+2 e Niño 4 constituem indicadores climáticos que apresentam os maiores valores significativos de correlação linear com a precipitação do sudeste da AS, que variam entre 0,2 e 0,3, para defasagens de até três meses. Os demais indicadores climáticos apresentam correlação significativa para defasagens de até dois meses para esta mesma região. A TSM na região de Niño 1+2, observada na área adjacente à costa do Equador, é o indicador climático que apresenta os valores mais altos de correlação linear com a precipitação do sudeste da AS, entre 0,3 e 0,4, para defasagem de um mês.

Embora o índice MEI apresente altos valores de correlação com a precipitação do norte ($0,4)$ e sudeste $(+0,2)$ da AS, para defasagens de até dois meses, a TSM da região de Niño $1+2$ apresenta valores de correlação relativamente altos $(\sim-0,3$ para a região norte e $+0,3$ para a 
região sul) para defasagens de até seis meses (na região norte), indicando, desta forma, maior potencial como variável preditora.

Considerando-se os resultados obtidos neste estudo (persistência de valores significativos de correlação linear) e as interações físico-dinâmica de associação entre eventos ENOS e a precipitação na AS, sugere-se que a região norte apresenta, em geral, maior potencial de previsibilidade do que a região sudeste em relação aos índices oceânicos considerados.

\section{BIBLIOGRAFIA}

ACEITUNO, P.; On the functioning of the Southern Oscillation in the South American sector. Part I: Surface climate. Monthly Weather Review, v.116, iss.3, p.505-524, March, 1988.

ACEITUNO, P.; El Niño, the Southern Oscilation, and ENSO: Confunsing names for a complex ocean-atmosphere interaction, Bulletin of the American Meteorological Society, v. 73, p.483485, april, 1992.

ALVES, L. M.; MARENGO, J.A.; CAMARGO JR.; H., CASTRO, C; Início da estação chuvosa na região sudeste do Brasil: Parte 1 - Estudos observacionais. Revista Brasileira de Meteorologia, v. 20, n.3, p. 385-394, Dezembro, 2005.

ALVES, L. M.; Clima da Região Centro-Oeste do Brasil. In: CAVALVANTI, I.F.A. et al. (org), Tempo e Clima no Brasil. São Paulo: Oficina de Textos, 2009, cap.15, p.235-241.

AMBRIZZI, T.; COELHO, C.A.S.; UVO, C.B. Exploring the impacts of the tropical Pacific SST on the precipitation patterns over South America during ENSO periods. Theoretical and AppliedClimatology, n.71, p.185-197, 2002.

AMBRIZZI, T.; EL Niño - Oscilação Sul e Teleconexões atmosféricas no hemisfério austral. Tese de Livre Docência, São Paulo: Universidade de São Paulo, 2003. 201p.

BJERKNESS, J.; A Possible response of the atmospheric Hadley circulation to Equatorial anomalies of ocean temperature. Tellus, v.18, iss.4, p.820-829, 1966.

BJERKNESS, J.; Atmospheric teleconnections from the equatorial Pacific. Monthly Weather Review, v.97, iss.3, p.163-172, March, 1969.

COELHO, C.A.S.; DRUMOND, A. R. M.; AMBRIZZI, T.; Estudo climatológico sazonal da precipitação sobre o Brasil em episódios extremos da Oscilação Sul. Revista Brasileira de Meteorologia, v.14, n.1, p.49-65, 1999.

COELHO, C.A.S.; Anomalias de Precipitação sobre a América do Sul e sua relação com a Temperatura de Superfície do Mar dos Oceanos Pacífico e Atlântico durante períodos extremos de El Niño-Oscilação Sul, Dissertação de Mestrado, São Paulo: Instituto de Astronomia Geofísica e Ciências Atmosféricas, Universidade de São Paulo, 2001. 254p.

COELHO, C.A.S; UVO, C.; AMBRIZZI, T.; Exploring the impacts of the tropical Pacific SST on the precipitation patterns over South America during ENSO periods. Theoretical and appliedclimatology, v.71, iss.3-4, p.185-197, 2002.

COSTA NETO, P.L. de O. (1939), Estatística. São Paulo: Edgard Blücher, 1977. 264p. 
DIAZ, H.F.; KILADIS, G.N. Atmospheric teleconnections associated with the extreme phases of the Southern Oscillation. In: DIAZ, H.F.; MARKGRAF, V. El Niño: Historical and paleoclimatic aspects of the Southern Oscillation. New York: Cambridge University Press, 1992. cap.2, p.7-28.

FERREIRA, N. J., RAMIREZ, M. V., GAN, M. A. Vórtices ciclônicos de altos níveis que atuam na vizinhança do nordeste do Brasil. In: CAVALVANTI, I.F.A. et al. (org), Tempo e Clima no Brasil. São Paulo: Oficina de Textos, 2009, cap.15, p.235-241.

GAN, M.A.; KOUSKY, V.E.; ROPELEWSKI, C.F. The South America Monsoon Circulation and its relationship to rainfall over West-Central Brazil, Journal of Climate, v. 17, p. 47-66, January, 2004.

GRIMM, A.M.; Sea surface temperatures in the Pacific and rainfall over part of Southern Brazil II: Dinamical mechanisms. Anais da Academia Brasileira de Ciências, v. 68, n. 1, p. 1116, 1996.

GRIMM, A.M.; FERRAZ, S. E. T.; GOMES, J. Precipitation Anomalies in Southern Brazil Associated with El Niño and La Niña events. Journal of Climate, v.11, iss. 11, p.2863-2880, November, 1998.

GRIMM, A.M.; BARROS, V.R., DOYLE, M.E. Climate Variability in Southern South America Associated with El Niño and La Niña Events. Journal of Climate, v.13, iss.1, p.35-58, January, 2000.

GRIMM, A.M. The El Niño Impact on the Summer Monsoon in Brazil: Regional processes versus remote influences. Journalof Climate, v.16, n.2, p.263-280, January, 2003.

GRIMM, A.M. Variabilidade interanual do clima no Brasil. In: CAVALVANTI, I.F.A. et al. (org), Tempo e Clima no Brasil. São Paulo: Oficina de Textos, 2009, cap.22, p.353-374.

HASTENRATH, S., HELLER, L. Dynamics of climatic hazards in north-east Brazil. Quarterly Journal of the Royal Meteorological Society, v.103, iss.435, p.77-92, 1977.

HOREL, J.D.; WALLACE; J.M. Planetary-Scale Atmospheric phenomena associated with the Southern Oscillation. American Meteorological Society, v. 109, p.813-829, April, 1981.

KANE, R.P. Relationship of El Niño-Southern Oscillation and Pacific Sea Surface Temperature with Rainfall in Various Regions of the Globe. Monthly Weather Review, v. 125, iss. 8, p. 1792-1800, August, 1997.

KAROLY, D.J. Southern Hemisphere circulation features associated with El Niño-Southern Oscillation events. Journal of Climate, v.2, p.1239-1252, November, 1989.

KOUSKY, V.E., CHU, P.S. Fluctuations in annual rainfall for Northeast Brazil, Jornal of the Meteorological Society of Japan, v. 56, n. 5, p. 457-465, October, 1978.

KOUSKY, V.E., Frontal influences on Northeast Brazil. Monthly Weather Review, v. 107, iss. 9, p. 1140-1153, September, 1979.

KOUSKY, V.E.; KAGANO, M.T., CAVALCANTI, I.F.A. A review of the Southern Oscillation: oceanic-atmospheric circulation changes and related rainfall anomalies. Tellus, 36A, p. 490504, 1984. 
LENTERS, J.D.; COOK, K.H. Summertime precipitation variability over South America: Role of the large-scale circulation, Monthly Weather Review, v. 127, p. 409-431, March, 1999.

LIEBMANN, B., ALLURED, D., Daily precipitation grids for South America. Bulletinof American Meteorological Society, v. 86, p. 1567-1570, November, 2005.

LOPES, F.Z. Relação entre o MEI (Multivariate ENSO Índex) e a precipitação pluvial no estado do Rio Grande do Sul. Dissertação de Mestrado. Pelotas: Universidade Federal de Pelotas, Faculdade de Meteorologia, 2006.159p.

MARENGO, J.A.; NOBRE, C.A.; Clima da Região Amazônica. In: CAVALVANTI, I.F.A. et al. (org), Tempo e Clima no Brasil. São Paulo: Oficina de Textos, 2009, cap.13, p.197-212.

MCPHADEN, M.J. et al. The tropical ocean-global atmosphere observing system: A decade of progress, Journal of Geophysical Research, v. 103, iss.C7, p. 14.169 - 14.240, June, 1998.

MCPHADEN, M.J. Genesis and Evolution of the 1997-1998 El Niño, Science, 283, 950-954, 1999.

MCPHADEN, M.J. El Niño and La Niña: causes and global consequences. Volume I, The Earth system: physical and chemical dimensions of global environmental change. In: MACCRACKEN, M.C., PERRY, J.S., Eds. Encyclopedia of Global Environmental Change, p. 353370, 2002.

MOLION, L.C.B. Climatologia dinâmica da região Amazônica: Mecanismos de Precipitação. Revista Brasileira de Meteorologia, v.2, p.107-117, 1987.

NIMER, E. Climatologia do Brasil. Rio de Janeiro: Secretaria de Planejamento da Presidência da República, Fundação Instituto Brasileiro de Geografia e Estatística, Diretoria Técnica, Superintendência de Recursos Naturais e Meio Ambiente, 1979, 421p.

QUADRO, M.F.L. et al. Climatologia de precipitação e temperatura. Revista Climanálise, Cachoeira Paulista, Climanálise especial, edição comemorativa de 10 anos, outubro,1996.

RASMUNSSON, E.M.; CARPENTER, T.H. The relationship between eastern equatorial Pacific sea surface temperature and rainfall over India and Sri Lanka. Monthly Weather Review, v.111, iss.3 p.517-528, March, 1983.

ROPELEWSKI, C.F; HALPERT, M.S. Global and regional scale precipitation patterns associated with the El Niño/Southern Oscillation. Monthly Weather Review., v.115, p.1606-1626, August, 1987.

ROPELEWSKI, C.F.; JONES, P.D. Notes and correspondence - An Extension of the TahitiDarwin Southern Oscillation Index. Monthly Weather Review, v.115, n.8, p.2161- 2165, September, 1987.

SATYAMURTY, P., NOBRE, C.A., SILVA DIAS, P. L. South America. IN: KAROLY, D.J., VICENT, D.G., Meteorology of the Southern Hemisphere, Boston: American Meteorological Society, v. 27, Issue 49, p. 119-139, December, 1998.

SMITH, T,M., REYNOLDS, R.W, PETERSON, T,C, LAWRIMORE, J. Improvements to NOAA's Historical Merged Land-Ocean Surface Temperature Analysis (1880- 2006). Journal of Climate, v. 21, p. 2283-2296, May, 2008. 
TRENBERTH, K.E. The definition of El Niño. Bulletin of the American Meteorological Society, v.78, n.12, p.2771-2777, December, 1997.

VAN LOON, H.; ROGERS, J.C. The seesaw in winter temperatures between Greenland and Northern Europe. Part I: General description. Monthly Weather Review, v.106, iss.3, p.296310, March, 1978.

VAN LOON, H.; MEEHL, G. A. The seesaw in winter temperatures between Greenland and Northern Europe. Part III: Teleconnections with lower latitudes. Monthly Weather Review, v.107, iss.9, p.1095-1106, September, 1979.

WALKER, G.T. (1924) Correlation in seasonal variations of weather, IX. A further study of world weather. Memoirs of the India Meteorological Department, v. XXIV, p.275-333, Calcutta, 1926. Disponível em: <http://www.rmets.org/publications/classic-papers>. Acesso em 01/11/2014.

WALKER, G.T.; BLISS, E.W. World Weather V. Memoirs of the Royal Meteorological Society, v. 4, n. 36, 1932. Disponível em: <http://www.rmets.org/publications/classic-papers>. Acesso em 01/11/2014.

WALLACE, J.M.; GUTZLER, D.S.; Teleconnections in the geopotential heigth field during the Northern Hemisphere winter. Monthly Weather Review, v.109, iss.4 p.784- 812, April, 1981.

WEBSTER, P.J.; CHANG, H.; Equatorial energy accumulation and emanation regions: Impacts of a zonally varyng basic state, Journal of the Atmospheric Sciences, v. 45, n. 5, p. 803-829, March, 1988.

WILKS, D.S. Statistical methods in the atmospheric sciences. 2.ed. San Diego, California: Academic Press, 2006. 627p.

WOLTER, K., TIMLIN, M.S. Monitoring ENSO in COADS with a seasonally adjusted principal component index. Proc. Of the 17th Climate Diagnostics Workshop, Norman, OK, NOAA/NMC/CAC, NSSL, Oklahoma. Clim. Survey, CIMMS and the School of Meteor., Univ. of Oklahoma, p.52-57, 1993. Disponível em <http://www.esrl.noaa.gov/psd/enso/mei/>. Acessoem 08/09/2014.

WOLTER K., TIMLIN, M.S, Measuring the strength of ENSO - How does 1997/98 rank? Weather, v.53, n.9, p.315-324, September, 1998.

Artigo submetido em 15/03/2015

Artigo aceito em 08/06/2015

